\title{
Mycorhization par Tuber melanosporum Vitt de vitroplants de Quercus robur L et Quercus pubescens Willd
}

\author{
A Boutekrabt ${ }^{1 *}$, G Chevalier ${ }^{2}$, JC Pargney ${ }^{1}, \mathrm{~J}$ Dexheimer ${ }^{1}$ \\ 1 Faculté des Sciences, Laboratoire de biologie des ligneux, université de Nancy-l, \\ BP 239, 54506 Vandœuvre-lès-Nancy ; \\ 2 Unité de mycologie, station d'agronomie et mycologie, INRA, 63039 Clermont-Ferrand, Cedex, France
}

(Reçu le 21 juin 1989 ; accepté le 29 novembre 1989)

Résumé - Les performances au champ des plants mycorhizés par la truffe sont limitées par l'hétérogénéité du matériel végétal jusqu'ici issu de semis. L'utilisation d'individus sélectionnés multipliés in vitro et de matériel fongique cloné permet de pallier ces inconvénients. II est possible maintenant de réaliser l'association mycorhizienne entre divers chênes (Quercus robur L, $Q$ pubescens Willd) et la truffe (Tuber melanosporum Vitt), aussi bien en conditions axéniques que gnotoxéniques; toutefois la multiplication du chêne pubescent en grandes quantités nécessite certaines améliorations techniques.

Quercus robur L / Quercus pubescens Willd / culture in vitro / synthèse axénique / synthèse gnotoxénique / Tuber melanosporum Vitt / vitroplant

Summary - Controlled mycorrhization of Quercus robur $L$ and Quercus pubescens Willd with Tuber melanosporum Vitt. The results in the field of plants carrying truffle mycorrhizae are limited by the heterogeneity of plant material which, up to now, has originated from seedlings (fig 1). The use of selected oak clones, multiplied in vitro and that of clonal "fungal" material should make it possible to reduce these disadvantages. From now on, it will be possible to achieve the mycorrhizal association between different oak species (Quercus robur $L, Q$ pubescens Willd) and the truffle (Tuber melanosporum Vitt), both in "axenic" and in "gnotoxenic" conditions (fig 2). Nevertheless, the in vitro multiplication on a large scale of Quercus pubescens requires further technical improvement.

Quercus robur L / Quercus pubescens Willd / in vitro culture / axenic synthesis / gnotoxenic synthesis / Tuber melanosporum Vitt / vitroplant

\section{INTRODUCTION}

L'utilisation de grandes quantités de plants (chênes et noisetiers) mycorhizés par la truffe (Tuber melanosporum Vitt) en conditions contrôlées a permis à la trufficulture française de partir sur de nouvelles bases (Chevalier et Grente, 1979). Bien que de bons résultats aient été obtenus (Chevalier, 1983), les performances du matériel végétal seraient cependant meilleures si les plants commercialisés actuellement pouvaient être plus homogènes.

Sur le plan phénotypique, un certain nombre de critères comme la forme des arbres, la vigueur, la précocité de débourrement, la sensibi- lité au gel, la résistance aux maladies, la résistance au calcaire, etc. s'avèrent très variables. Au niveau racinaire, cette variabilité se répercute sur l'aptitude à la mycorhization et, par conséquent, sur la production de truffes.

Certes, un début de sélection du matériel végétal a bien été entrepris depuis plusieurs années (Chevalier et Grente, 1979). Par ailleurs, dans la mesure du possible, les graines et les corps fructifères destinés à la préparation des plants mycorhizés ont été différenciés en fonction de leurs origines géographiques et écologiques. Malgré tout, cette sélection s'est révélée insuffisante, d'une part à cause du mode de multiplication des plants truffiers qui proviennent de

\footnotetext{
" Correspondance et tirés à part
} 
semis de glands et d'autre part à cause de l'hétérogénéité du matériel fongique servant d'inoculum (suspensions sporales obtenues par broyat de mélanges d'ascocarpes).

L'élaboration d'un plan de sélection efficace implique simultanément : la production de clones d'essences truffières, la production de clones de Tuber, la réalisation de l'association mycorhizienne en conditions contrôlées.

Depuis le début des années 70, I'INRA de Clermont-Ferrand dispose de clones de différents Tuber d'origines géographique et écologique variées, susceptibles d'être multipliés aussi bien en milieu solide que liquide (Chevalier, 1972). A partir de 1972, des synthèses axéniques ont pu être réalisées entre des plantules issues de semis et des cultures mycéliennes de différents Tuber (Chevalier, 1973 ; Palenzona et al, 1972). L'étape suivante a été la mycorhization par la truffe, en conditions gnotoxéniques, de clones de chênes obtenus par bouturage (Chevalier et al, 1978).

Avec la production récente de chênes pédonculés par micropropagation à l'université de Nancy (Favre et Juncker, 1986) et leur mycorhization in vitro par divers Basidiomycètes (Lei et Dexheimer, 1987), les conditions favorables se sont trouvées réunies pour renouveler l'expérience avec la truffe.

Nous rappelons qu'un travail similaire sur le noisetier est effectué par l'équipe de l'INRA de Bordeaux (Salesses et al, 1989).

Les raisons du choix des chênes tiennent également au fait qu'ils constituent d'excellentes essences truffières, notamment le chêne pubescent. Cette espèce présente certains avantages par rapport au noisetier : une meilleure résistance à la sécheresse, un drageonnement nul ou faible, une sensibilité faible aux maladies (excepté l'oïdium), une croissance et même une production précoces de truffes dans certains sols.

\section{MATÉRIEL ET MÉTHODES}

\section{Matériel}

\section{Les vitroplants}

Deux espèces de chênes sont cultivées in vitro : $Q$ robur et $Q$ pubescens. Les vitroplants de $Q$ robur sont obtenus par micropropagation de boutures issues de semis de glands provenant de l'Arboretum du CNRF de Champenoux et cultivés sur milieu de Favre et Juncker (1986) (fig 1). Ceux de $Q$ pubescens, transmis par I'INRA de Clermont-Ferrand, sont obtenus par la même méthode, mais sur un milieu dérivé de celui de Murashige et Skoog (1962). Les vitroplants sont

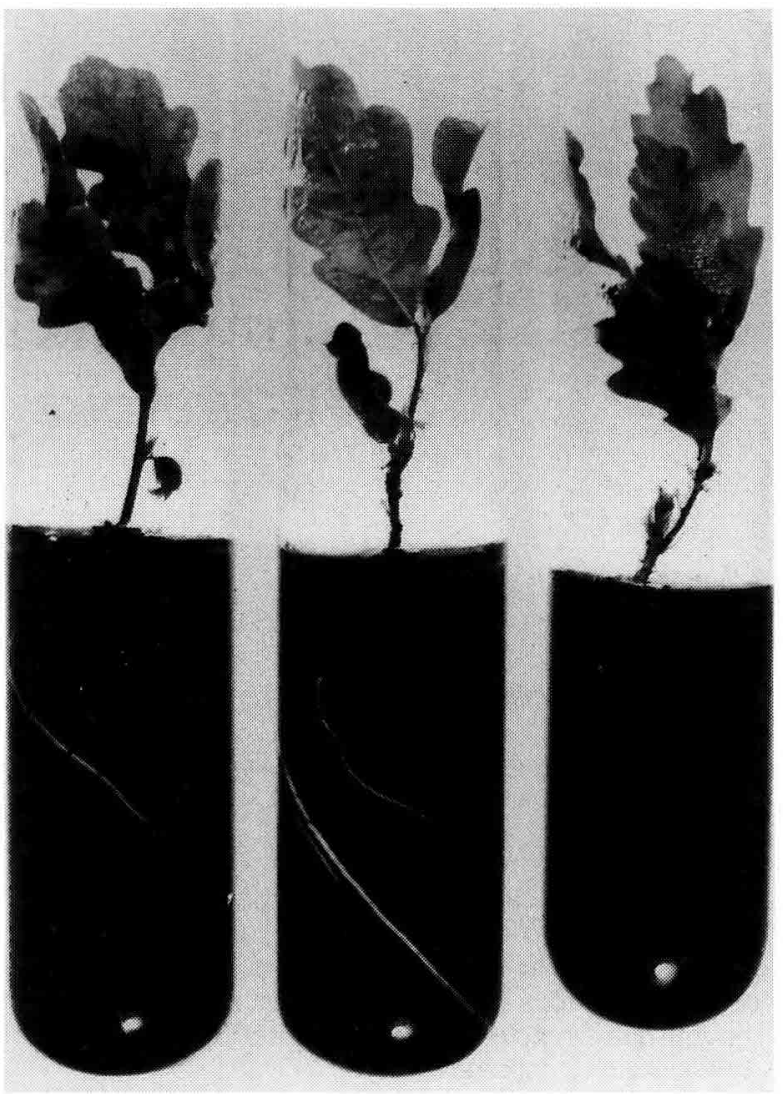

Fig. 1. Vitroplants de Quercus robur sur milieu d'expression racinaire en tube.

cultivés sur milieu de multiplication pendant 5 à 6 semaines, puis, après induction racinaire, sont transférés sur milieu d'expression qui ne diffère du milieu d'induction que par l'absence d'auxines et par l'adjonction de charbon actif.

Les vitroplants âgés de 3 mois présentent une partie aérienne à 2 vagues de croissance en moyenne et un système racinaire bien développé.

\section{Le partenaire fongique}

Deux types d'inoculum sont testés : des suspensions d'ascospores obtenues par broyage de fragments de carpophores (Chevalier et al, 1973); des cultures mycéliennes sur milieu gélosé identique à celui utilisé classiquement à I'INRA de Clermont-Ferrand (Chevalier, 1972).

\section{Mycorhization contrôlée}

\section{Les synthèses}

La mise en présence du champignon et des racines de la plante est réalisée soit directement in vitro (conditions axéniques), soit à la sortie des tubes de culture (conditions gnotoxéniques).

\section{Synthèse axénique}

Elle est effectuée en boîte de Petri carrée $(11,5 \mathrm{~cm}$ de côté) sur un milieu de culture gélosé analogue à celui 
déjà utilisé pour les synthèses avec $T$ melanosporum en conditions hydroponiques (Chevalier et Desmas, 1977) (fig 2).

Les plantules sont sorties stérilement des tubes sous hotte à flux laminaire; les racines sont lavées à l'eau distillée stérile pour les débarrasser de la gélose; les vitroplants sont alors transférés dans les boîtes de Petri et des fragments de culture mycélienne sur agar $\left(1 \mathrm{~cm}^{2}\right)$ sont plaqués sur les racines.

Les boîtes de Petri sont alors scellées avec du papier adhésif pour éviter la dessication du milieu de culture et déposées en chambre d'incubation. Ce système permet un suivi facile de la mycorhization.

\section{Synthèse gnotoxénique}

Les vitroplants âgés de 3 mois sont préalablement acclimatés en mini-serre, pendant environ 2 mois, sur un substrat composé de tourbe et vermiculite $(1 / 3: 2 / 3 \mathrm{v} / \mathrm{v})$.

Le substrat est stérilisé une $1^{\text {re }}$ fois à $120^{\circ} \mathrm{C}$ pendant $30 \mathrm{~min}$, puis une $2^{\circ}$ fois, $24 \mathrm{~h}$ plus tard, après imbibition avec une solution nutritive (Coïc et Lesaint, 1973).

La transplantation se fait rapidement, compte tenu des effets néfastes du desséchement, après lavage des racines pour les débarrasser de gélose. Les plantules sont maintenues dans l'atmosphère confinée de la mini-serre jusqu'au début de la reprise (environ 1 mois), puis le couvercle de la mini-serre est ouvert progressivement pour les habituer à une atmosphère plus sèche.

Après acclimatation, les plantules sont transférées en conteneurs INRA M (Ricadacker, 1986), dans un mélange à base de tourbe et de vermiculite dérivé de celui utilisé pour la production de plants mycorhizés à grande échelle (Chevalier, 1984). L'inoculation est réalisée au moment du repiquage par apport de la suspension sporale au contact du système racinaire.

\section{Conditions de culture}

En conditions axéniques, les boîtes de Petri sont maintenues au laboratoire sous tubes fluorescents en

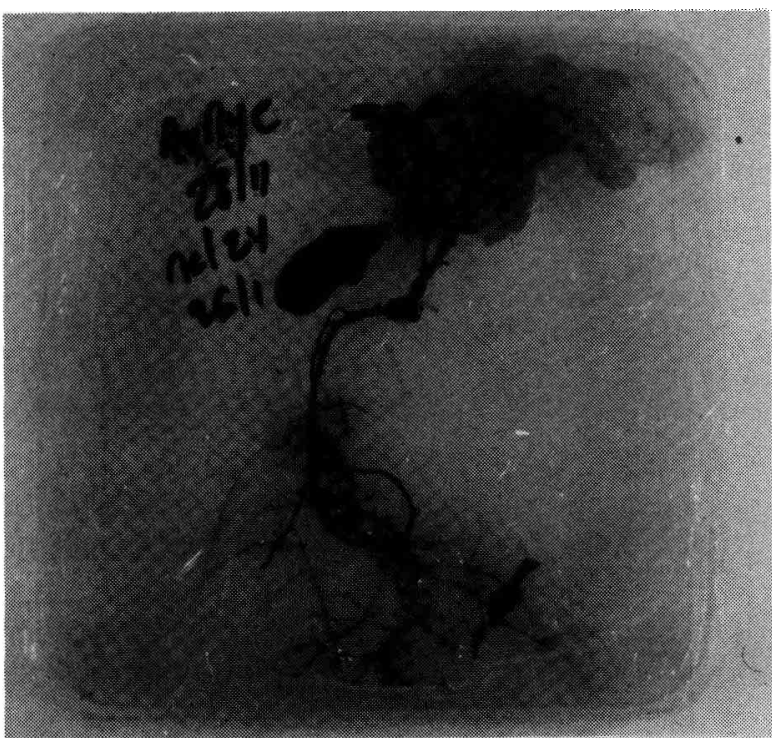

Fig. 2. Synthèse ectomycorhizienne sur milieu gélosé en conditions axéniques. lumière continue, à température ambiante. En conditions gnotoxéniques, les conteneurs sont placés en serre vitrée, non climatisée, à la lumière naturelle ; l'arrosage est effectué à l'eau du robinet.

\section{Techniques de contrôle}

Le contrôle de la mycorhization s'effectue sous la loupe binoculaire, à travers le couvercle de la boîte de Petri. Des échantillons, destinés à l'observation cytologique, sont prélevés. Les techniques utilisées pour la microscopie électronique à transmission sont celles décrites par Dexheimer et al (1986). Des coupes semifines, réalisées à partir de matériel destiné à la microscopie électronique, sont recueillies sur une lame de verre, colorées au bleu de toluidine à $\mathrm{pH}$ alcalin et observées en microscopie photonique.

\section{RÉSULTATS}

\section{Synthèse axénique}

Dès le $28^{\ominus}$ jour après l'inoculation, il est possible d'observer les premières mycorhizes en forme de massues de couleur marron clair typiques (fig 3 ). Le pourcentage de plants mycorhizés est de l'ordre de $22 \%$. Ce taux relativement faible s'explique par la prolifération de bactéries. Celles-ci sont issues de certains isolats de Tuber car elles

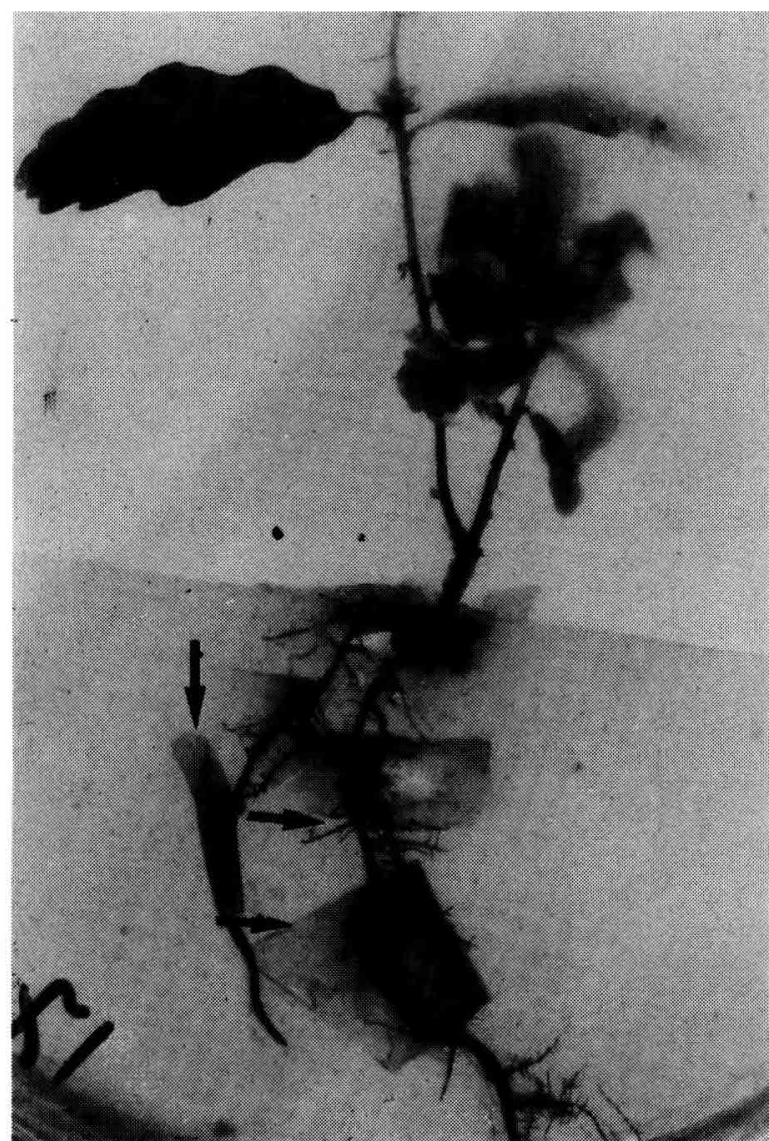

Fig. 3. Mycorhizes obtenues en conditions axéniques avec mycélium plaqué contre les racines (flèche). 
leur sont associées ; toutefois, des contaminations lors des manipulations peuvent intervenir malgré les précautions prises. II en résulte une réduction notable ou même la suppression de la croissance du champignon. Cependant, les systèmes aérien et racinaire des vitroplants sont correctement développés.

\section{Synthèse gnotoxénique}

Le contrôle a lieu durant la $1^{\text {re }}$ quinzaine de septembre, soit un peu plus de 4 mois après l'inoculation. Le système racinaire est bien développé et abondamment ramifié ; des grappes de mycorhizes sont localisées dans la partie supérieure du système racinaire. Le pourcentage de plants mycorhizés est de l'ordre de $85 \%$. Le substrat de culture assure donc à la fois une croissance satisfaisante des plants et une bonne mycorhization. Les mycorhizes obtenues sont de couleur marron et lisses. Le fait qu'au moment du contrôle elles soient déjà très ramifiées indique que la mycorhization n'est pas récente.

\section{Contrôle des mycorhizes obtenues}

L'examen des coupes semi-fines au microscope photonique révèle un manteau formé de plusieurs couches et, entre les cellules corticales, un réseau de Hartig bien développé (fig 4). Ces observations sont confirmées par l'étude en microscopie électronique. Le manteau externe est constitué de 5 à 7 couches de cellules mortes

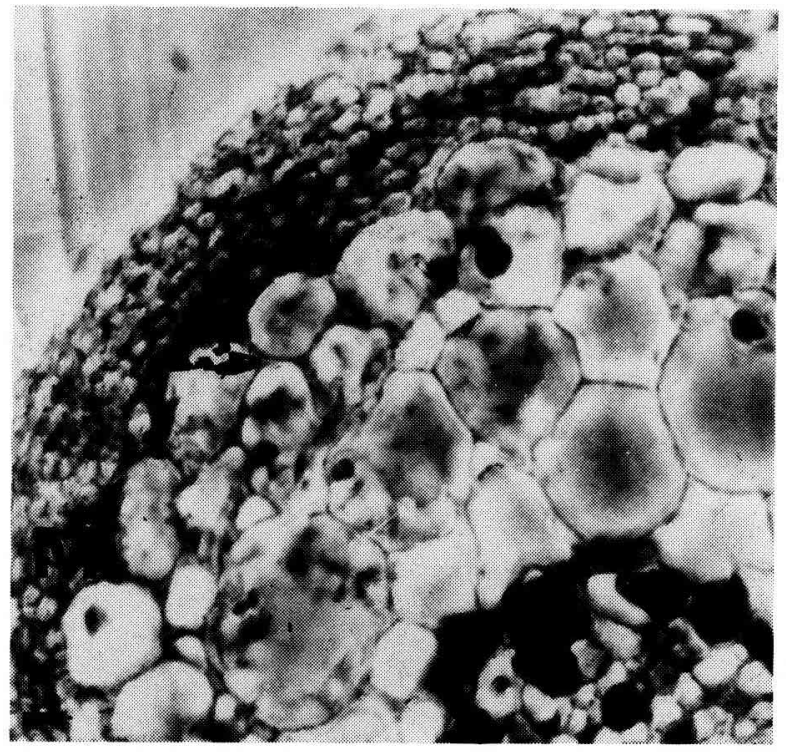

Fig. 4. Coupe semi-mince de mycorhize de Tuber melanosporum. Le manteau (M) est épais avec plusieurs couches d'hyphes. Les hyphes s'insinuent entre les cellules corticales et forment le réseau de Hartig (G $\times 4500)$. dont les sections sont plus ou moins allongées (fig 5 et 7). Fréquemment des bactéries leur sont associées (fig 7). Le manteau interne est formé de cellules vivantes, de sections également allongées (fig 5 et 6 ) et qui présentent parfois entre elles des masses denses aux électrons (fig 6). En continuité avec le manteau (fig 6), le réseau de Hartig est également constitué d'hyphes vivantes entourant les cellules corticales fortement vacuolisées (fig 8).

\section{DISCUSSION ET CONCLUSION}

Les observations macroscopiques complétées par celles du microscope photonique et électronique confirment l'identité des mycorhizes et leur similitude avec celles observées dans la nature ou synthétisées en conditions axéniques ou gnotoxéniques (Chevalier, 1973; Chevalier et al, 1973 ; Pargney et Leduc, 1990).

Après les résultats de Grellier et al (1984), Strullu et al (1984), Strullu et al (1986), Poissonnier (1986), Lei et Dexheimer (1987), Reynoird et Strullu (1987), ceux obtenus ici démontrent que la voie du clonage par micropropagation associée à la mycorhization contrôlée pourrait être une solution d'avenir pour le chêne et la truffe.

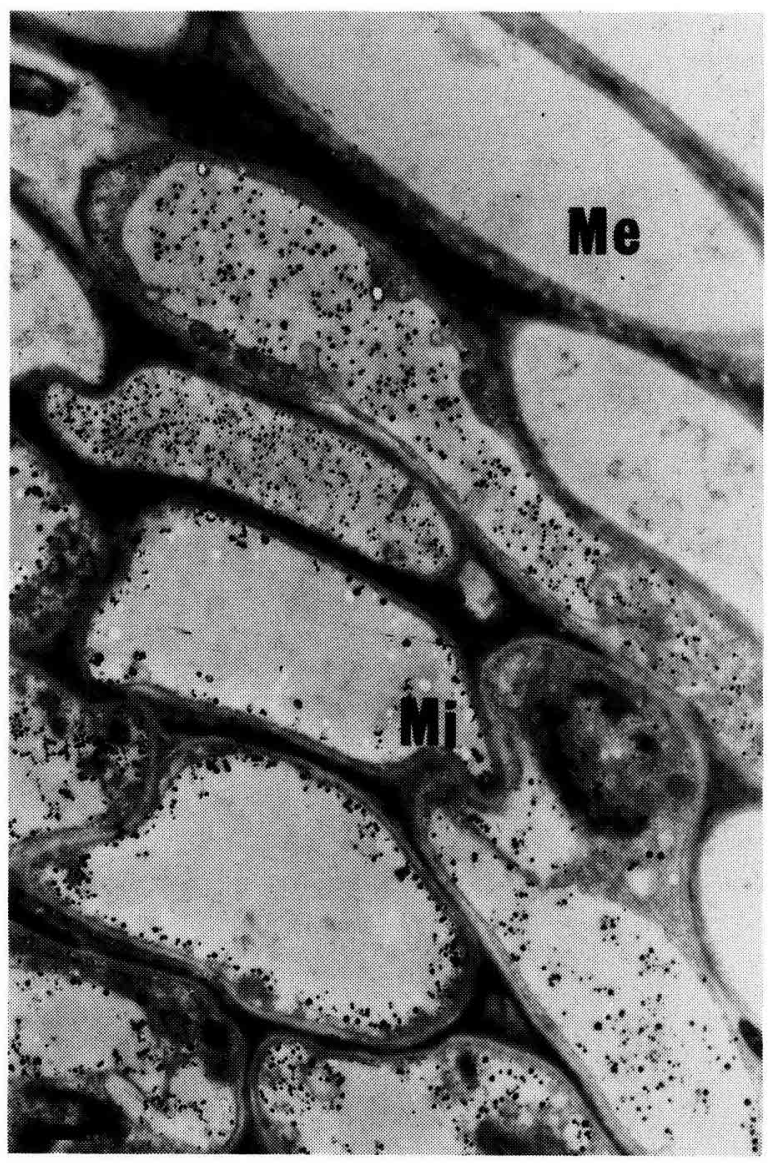

Fig. 5. Manteau externe (Me) et manteau interne (Mi) en microscopie électronique ( $G \times 5000)$. 


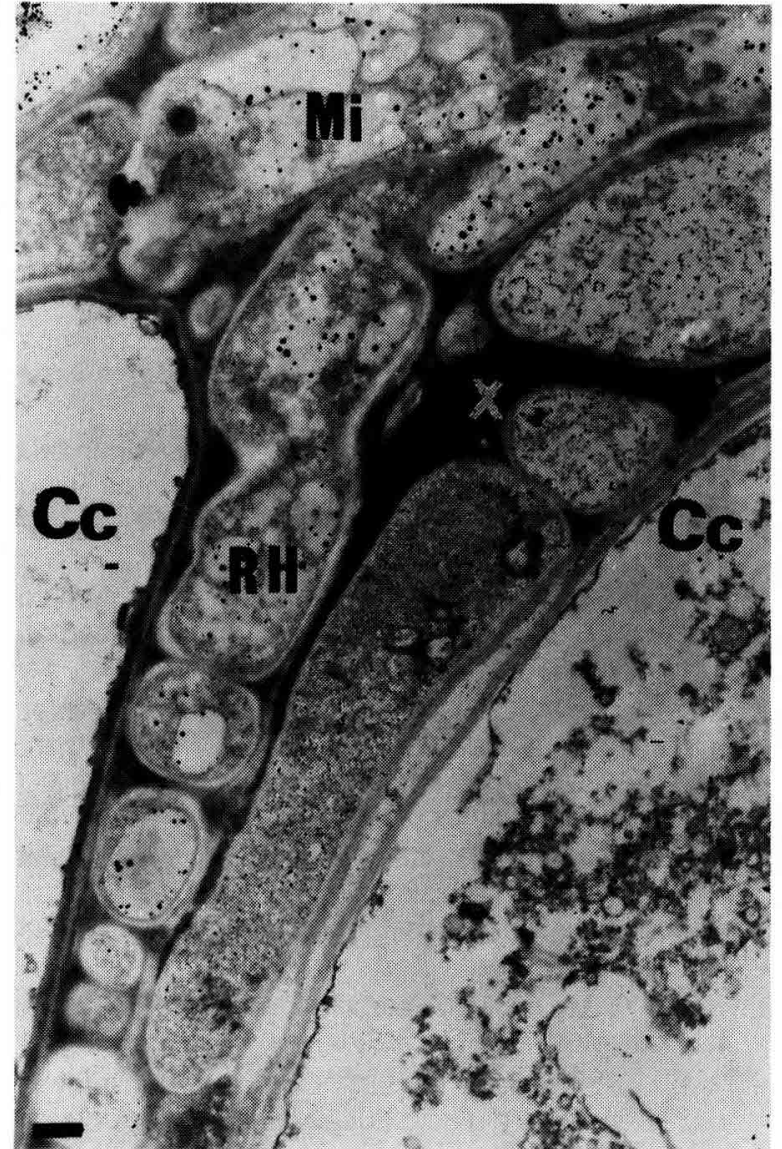

Fig. 6. Manteau interne (Mi) et début de réseau de Hartig (RH) s'insinuant entre les cellules corticales (Cc). Des masses denses $(X)$ sont présentes entre les cellules ( $G \times 4500)$.

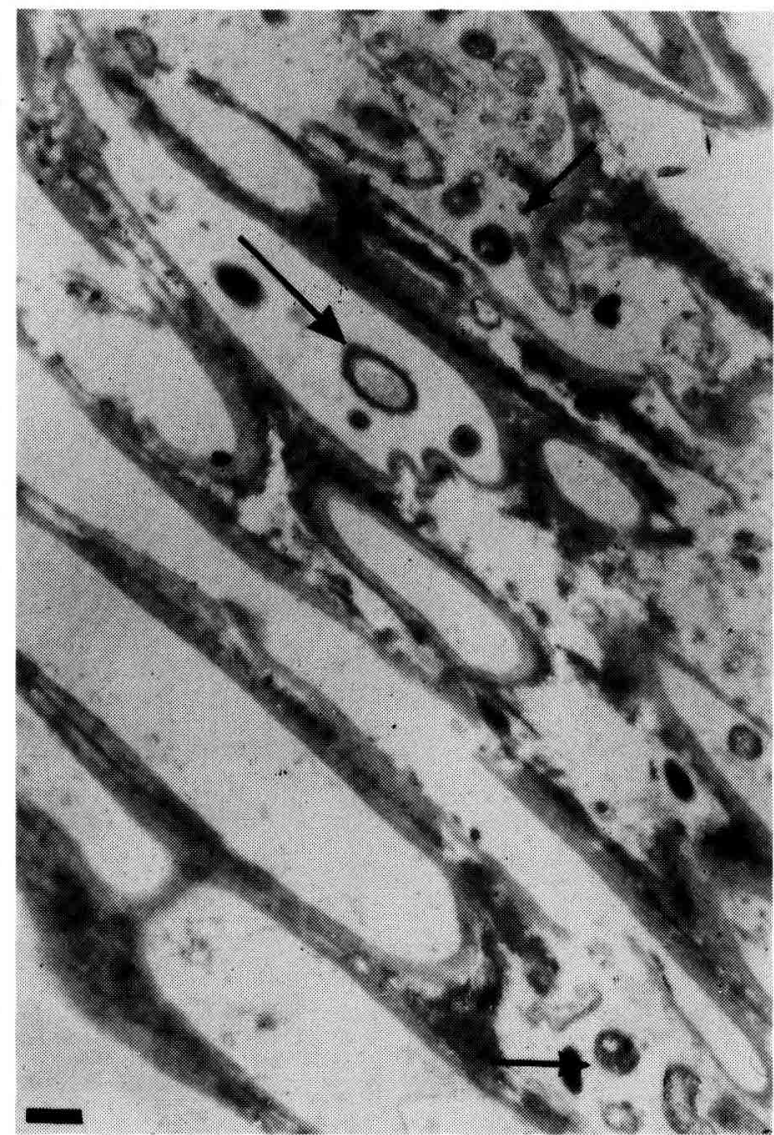

Fig. 7. Dans les cellules corticales, les bactéries sont toujours présentes (flèche) $(\mathrm{G} \times 5000)$.

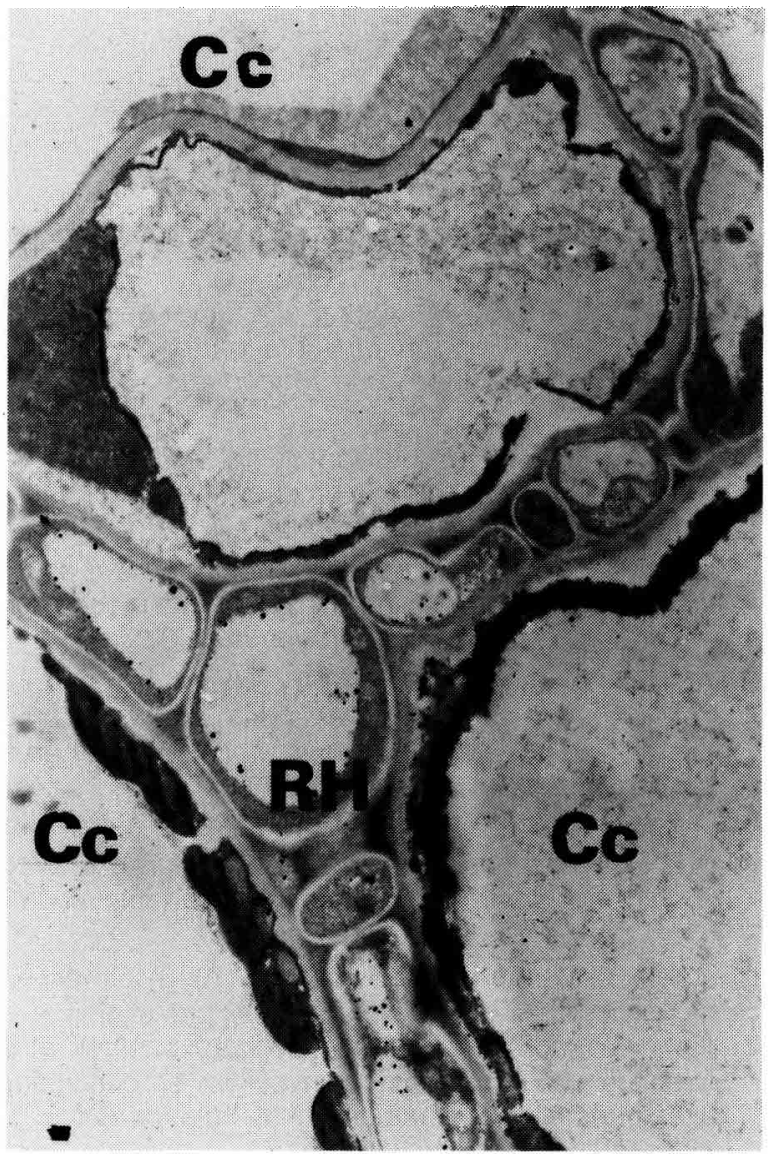

Fig. 8. Réseau de Hartig $(\mathrm{RH})$ entourant les premières cellules corticales (Cc) (G X 5000$)$.

Nous maîtrisons maintenant les phases de multiplication in vitro des chênes pédonculés et pubescents, de mycorhization contrôlée et de sortie de l'in vitro. Toutefois, l'allongement du chêne pubescent nécessite encore l'amélioration de certaines conditions de culture (par exemple, la température). La truffe peut être associée au matériel végétal aussi bien in vitro qu'à la sortie du tube.

Les clones produits in vitro peuvent être inoculés ou éventuellement remis sans symbiote, après sevrage, aux pépiniéristes qui auraient alors la possibilité d'appliquer leur propre technique d'élevage et de mycorhization. II reste à évaluer les potentiels trufficoles de ces vitroplants mis au champ ; il faut également les comparer à ceux des vitroplants issus de chênes à forte production de truffes. Ces deux objectifs doivent constituer la prochaine étape de notre travail.

\section{REMERCIEMENTS}

Ce travail a bénéficié d'une subvention européenne dans le cadre du Plan d'intégration méditerranéen et du projet «Relance de la trufficulture en Aquitaine". 


\section{RÉFÉRENCES}

Chevalier G (1972) Obtention de cultures de mycélium de truffe à partir du carpophore et des mycorhizes. CR Acad Agric Fr 12, 981-989

Chevalier G (1973) Synthèse axénique des mycorhizes de Tuber brumale Vitt à partir de cultures pures du champignon. Ann Phytopathol 5, 2, 163182

Chevalier G (1983) Production de truffes à partir de plants mycorhizés selon le procédé INRA : premiers résultats. Bull FNPT 6, 33-50

Chevalier G (1984) Une nouvelle méthode de production de plants mycorhizés par la truffe : l'inoculation en motte roulée Melfert. Agronomie 4, 2, 211

Chevalier G, Desmas C (1977) Mycorhization par Tuber melanosporum de plants de Quercus pubescens en culture hydroponique sensu stricto. Ann Phytopathol 9, 4, 532

Chevalier G, Grente J (1979) Application pratique de la synthèse ectomycorhizienne : production à grande échelle de plants mycorhizés par la truffe. Mushroom Sci 10, 2, 483-505

Chevalier G, Grente J, Pollacsek A (1973) Obtention de mycorhizes de différents Tuber par synthèse à partir de spores en conditions gnotoxéniques et à partir de cultures pures de mycélium en conditions axéniques et gnotoxéniques. Ann Phytopathol 5, 1, 107-108

Chevalier G, Grente J, Garbaye J, Ferrapy I (1978) Mycorhization par la truffe (Tuber melanosporum Vitt) de boutures racinées de chêne rouvre (Quercus petraea M. Liebl). CR Congrès IUFRO, Nancy, septembre 1978

Coïc Y, Lesaint $C$ (1973) La nutrition minérale en horticulture avancée. Rev Hortic (Paris) 2 316, 29-34

Dexheimer J, Aubert-Dufresne MP, Gerard J, Le Tacon F, Mousain D (1986) Étude de la localisation structurale des activités phosphatasiques acides dans deux ectomycorhizes Pinus nigra nigricans/Hebe- loma crustuliniforme et Pinus pinaster/Pisolithus tinctorius. Bull Soc Bot Fr 133, 343-352

Favre JM, Juncker B (1986) In vitro growth of buds taken from seedlings and adult plant material in Quercus robur L Plant Cell, Tissue Organ Cult 8, 49-60

Grellier B, Letouze R, Strullu DG (1984) Micropropagation of birch and mycorrhizal formation in vitro. New Phytol 97, 591-599

Lei J, Dexheimer J (1987) Résultats préliminaires concernant la mycorhization contrôlée de vitroplants de chêne (Quercus robur L) Ann Sci For (Paris) 44, 3, 315-324

Murashige T, Skoog F (1962) A revised medium for rapid growth bioassays with tobacco tissue cultures. Physiol Plant 15, 473-497

Palenzona M, Chevalier G, Fontana A (1972) Sintesi micorrizica tra Tuber brumale Vitt, $T$ melanosporum Vitt, $T$ rufum Pico, in colture di micelio, e semenzali di conifere e latifoglie. Allionia 18, 41-52

Pargney JC, Leduc JP (1990) Étude ultrastructurale de l'association mycorhizienne Noisetier/Truffe (Corylus avellana / Tuber melanosporum). Bull Soc Bot Fr (sous presse)

Poissonnier M (1986) Mycorhization in vitro de clones d'Eucalyptus. Ann Rech Sylv AFOCEL, 81-93

Reynoird JP, Strullu DG (1987) Obtention d'ectomycorhizes chez les plants d'Eucalyptus cultivés in vitro. Rev For Fr 39, 33-37

Salesses G, Chassagne M, Olivier JM, Guinberteau J (1989) Le clonage des noisetiers truffiers. Intérêt des vitroplants. Congrès de la trufficulture, Saintes. Bull FNPT 11, 15-21

Strullu DG, Letouze R, Grellier B (1984) Micropropagation et mycorhization in vitro : concepts et réalisations. CR Acad Agrico Fr 11, $1331-1337$

Strullu DG, Grellier B, Marciniak D, Letouze R (1986) Micropropagation of Chesnut and conditions of mycorrhizal syntheses in vitro. New Phytol 102, 95101 